\title{
MERS-CoV and Its Impact in the Middle East/Arab World
}

\author{
Gouri R. Banik, Jen Kok, and Harunor Rashid
}

\section{Contents}

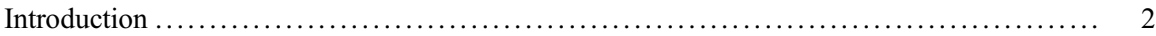

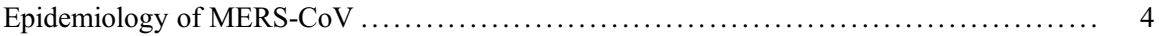

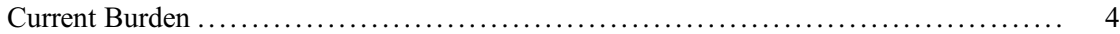

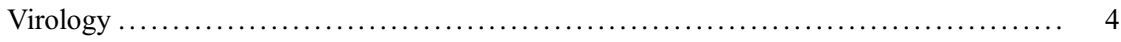

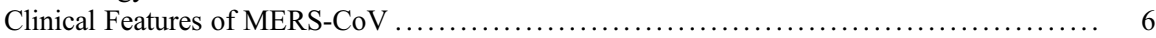

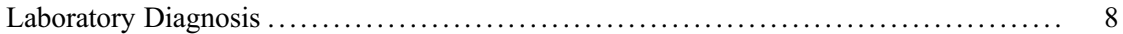

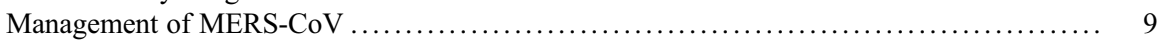

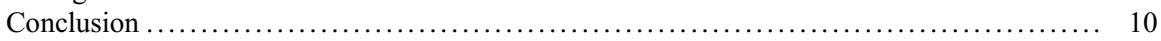

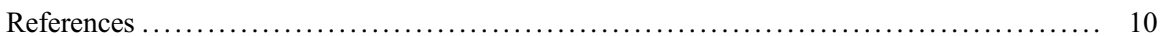

G. R. Banik ( $\bowtie)$

National Centre for Immunisation Research and Surveillance, The Children's Hospital at Westmead, Kids Research, Sydney Children's Hospitals Network, Westmead, NSW, Australia

School of Medical and Molecular Biosciences, The i3 Institute, Faculty of Science, University of Technology, Sydney, Ultimo, NSW, Australia

e-mail: GouriRani.Banik@health.nsw.gov.au; GouriRani.Banik@alumni.uts.edu.au

\section{J. Kok}

Centre for Infectious Diseases and Microbiology Laboratory Services, NSW Health PathologyInstitute of Clinical Microbiology and Medical Research, Westmead Hospital, Westmead, NSW, Australia

e-mail: Jen.Kok@health.nsw.gov.au

H. Rashid

National Centre for Immunisation Research and Surveillance, The Children's Hospital at Westmead, Kids Research, Sydney Children's Hospitals Network, Westmead, NSW, Australia

Discipline of Child and Adolescent Health, Faculty of Medicine and Health, The University of Sydney, Sydney, NSW, Australia

e-mail: harunor.rashid@health.nsw.gov.au 


\section{Abstract}

Middle East respiratory syndrome coronavirus (MERS-CoV) that causes a severe lower respiratory tract infection in humans is considered a pandemic threat to the Gulf region. In this chapter, the latest information on MERS-CoV biology, epidemiology, transmission dynamics, clinical features, diagnosis, treatment, and preventive strategy are summarized. The current epidemiology is characterized by slow and sustained transmission with occasional sparks in the Middle East. Although the transmission cycle of MERS-CoV is not fully understood yet, the dromedary camel is considered to be the intermediate host of the virus and believed to play an important role in the epidemiology of the virus. MERS-CoV is particularly severe in men with comorbidities and rare in children. Several vaccine approaches have shown efficacy in animal models and begun to enter clinical trials. Travellers to the Middle East may benefit from health education on avoidance of exposure to camels and ill persons and refraining from consuming raw camel products.

\section{Keywords}

Arab World · Bat · Dromedary camel $\cdot$ Gulf region · MERS-CoV · Middle East · SARS

\section{Introduction}

Middle East respiratory syndrome coronavirus (MERS-CoV) was first isolated in 2012 from a 60-year old Saudi man who died of severe lower respiratory tract infection and renal failure (Zaki et al. 2012). MERS-CoV is now an epidemic threat to the Gulf region and elsewhere. In the beginning, it was variously known as novel coronavirus (nCoV), London1_novel CoV 2012, and Saudi SARS (Severe Acute Respiratory Syndrome), but was finally named MERS-CoV by consensus (De Groot et al. 2013).

After the first description, MERS-CoV has been reported in more than 27 countries, with the majority of cases in Saudi Arabia; a sizeable cluster has also been reported in South Korea (Su et al. 2015) (Fig. 1). Compared to other coronaviruses, such as SARS, MERS-CoV is more fatal (SARS 10\% vs. MERS-CoV 37\%), particularly in those with preexisting medical comorbidities (Banik et al. 2015). To date, most individuals infected with MERS-CoV (>85\%) either reside in or report a history of travel to the Middle East, which is in sharp contrast with SARS which is not known to affect the region (Fig. 2).

It remains unclear why MERS-CoV is primarily limited to the Middle East. It is thought to be related to the widespread distribution of dromedary camels (the blamed intermediate host of the disease) in the region, even though the precise role of camels in the transmission is yet to be established (Alagaili et al. 2014; Chan et al. 2013; Yusof et al. 2015; Zumla et al. 2015). Serological evidence suggests MERS-CoV has been circulating among dromedary camels for at least two to three decades (Muller 


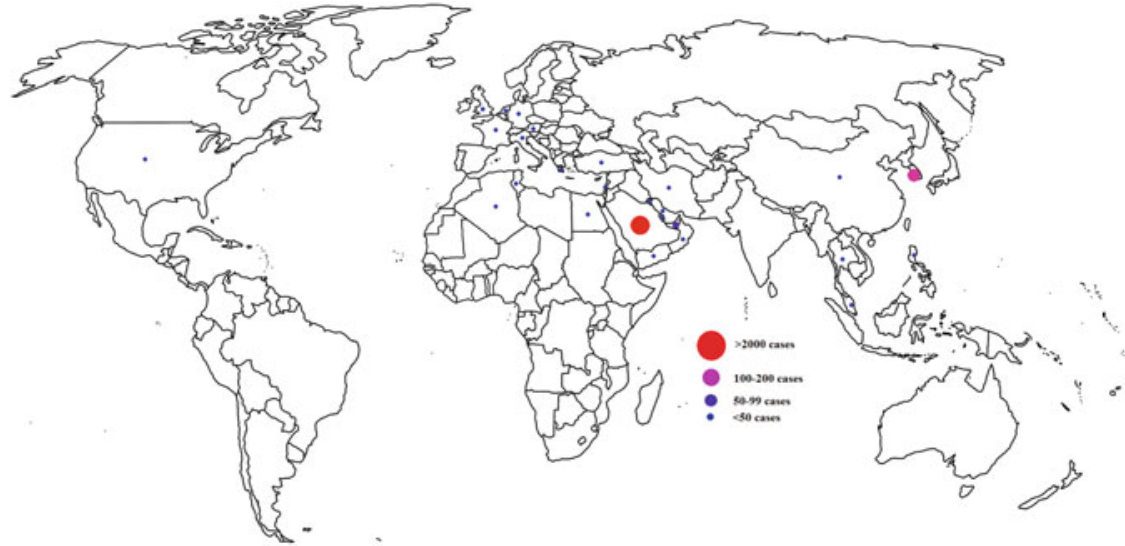

Fig. 1 Global distribution of MERS cases (as of December 2019)

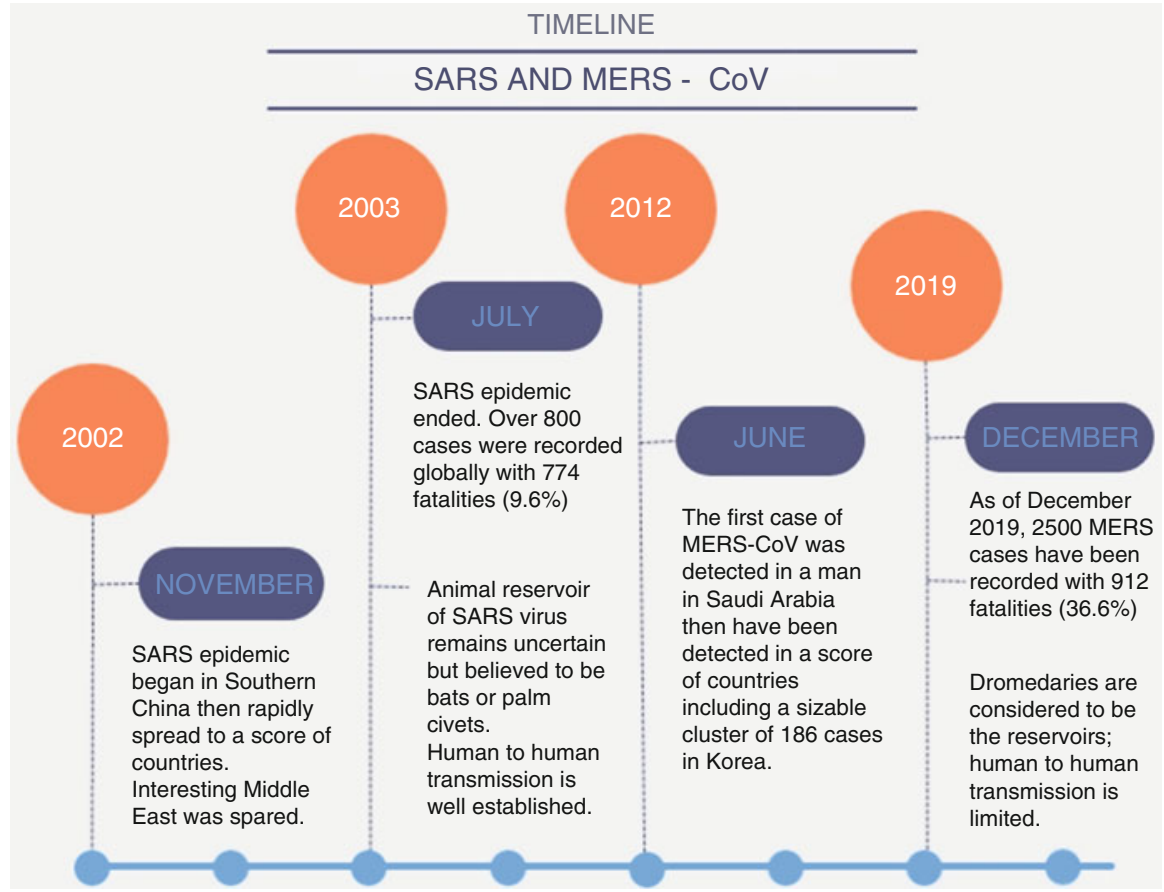

Fig. 2 Timeline: SARS versus MERS-CoV

et al. 2014); however, bats are considered the reservoirs of the beta-coronaviruses $(\beta-\mathrm{CoVs})$ including MERS-CoV (Zumla and Hui 2014), whereas dromedary camels are thought to be intermediate hosts (Van Doremalen and Munster 2015; Memish 2014; Zumla et al. 2015; Zumla and Hui 2014). 
MERS-CoV is believed to be transmitted via the respiratory (droplet and airborne) route and direct contact, but the dominant mode of transmission remains unknown. Currently, airborne transmission and contact precaution procedures (including hand hygiene, the use of P2 masks/respirators, gowns, gloves, and eye protection) are recommended for management of persons with suspected or confirmed MERS-CoV.

\section{Epidemiology of MERS-CoV}

\section{Current Burden}

About 2,500 cases of MERS-CoV with 912 deaths in 27 countries have been reported for the period June 2012 to December 2019 (ECDC 2019). During the same period, there 2105 cases of MERS-CoV in Saudi Arabia (FAO 2019), with $36 \%$ cases being reported from Riyadh (Al-Ahmadi et al. 2019). The incidence of MERS-CoV infections is highest in people aged $\geq 60$ years; males are twice as likely to be infected than females (Shapiro et al. 2016). Although the seasonality of MERS$\mathrm{CoV}$ infection is unclear, one report links it to the camel breeding season. As such, the peak season for MERS-CoV infections and transmission theoretically is summer; however, many MERS-CoV infections also occur in winter. Hot climates in the Arabian Peninsula and Sub-Saharan African regions are believed to contribute to the spread of MERS-CoV infections across those geographical regions (Ramadan and Shaib 2019).

\section{Virology}

MERS-CoV is a positive-sense, enveloped, single-stranded RNA virus belonging to the genus $\beta-\mathrm{CoVs}$ and a member of the subfamily Coronavirinae. Its genome is about $30-\mathrm{kb}$ in size (Banik et al. 2015). A sequence comparison study showed about $90 \%$ sequence homology of MERS-CoV with bat coronaviruses HKU4 and HKU5 (lineage 2C) in contrast to SARS coronavirus (lineage 2B) (Song et al. 2014; De Groot et al. 2013). MERS-CoV is the first lineage $2 \mathrm{c} \beta-\mathrm{CoV}$ to infect humans (De Groot et al. 2013; Cunha and Opal 2014; Song et al. 2015). It is also genetically related to other $\beta$-CoVs isolated from bats in China, Mexico, Hong Kong, and Europe (Yang et al. 2014; Wang et al. 2014; Cotten et al. 2013).

Phylogenetic analyses revealed that of 182 full-length genomes or genome fragments of MERS-CoV sequenced, 94 are from humans and the rest from dromedary camels (Chafekar and Fielding 2018). MERS-CoV genomes belong to two clades: A and B; majority of the viruses belong to clade B (Chafekar and Fielding 2018). The first $5^{\prime}$ two-thirds of the MERS-CoV genome consists of the replicase complex Open Reading Frame (ORF) $1 \mathrm{a}$ and ORF 1b. The $3^{\prime}$ encodes the remaining one-third of the genome consisting structural proteins: spike (S), envelope (E), membrane $(\mathrm{M})$, and nucleocapsid $(\mathrm{N})$. The genome also contains five accessory 
proteins (ORF3, ORF4a, ORF4b, ORF5, and ORF8b) that are not required for genome replication, but has role in pathogenesis (Chafekar and Fielding 2018). The flanking regions of the genome contain the $5^{\prime}$ and $3^{\prime}$ untranslated regions (UTR) (Lu et al. 2015). The full genome of MERS-CoV from dromedaries has 99.9\% homology with human clade B MERS-CoV and 94\% homology with bat coronaviruses (Arabi et al. 2014; Senga et al. 2017).

Electron microscopy reveals that the MERS-CoV virion contains club-like projections, representing viral spike peplomers, emanating from the viral membrane. Unlike SARS virus that enters the target cells via angiotensin converting enzyme 2 (ACE2), MERS-CoV binds to human dipeptidyl peptidase 4 (hDPP4; also known as CD26) via the receptor binding domain (RBD) on its spike glycoprotein (Wang et al. 2013). It is noteworthy that both ACE2 and hDPP44 are expressed in human kidneys. MERS-CoV utilizes host proteases to gain entry into lung cells (Banik et al. 2015). The spike protein on the viral envelope is activated by a protease, called furin, and mediates membrane fusion which eventually supports virus entry into host cells (Eckerle et al. 2013). The receptor and proteases transform the virus to a membrane fusion-active form. A major change in the conformation of the $\mathrm{S}$ protein, which is also a primary determinant of tissue tropism, host range, and pathogenesis, initiates this process. Consequently, protease inhibitors (e.g., camostat) are found to block MERS-CoV cell entry (Shirato et al. 2014). Of note, hDDP4 is expressed on cell surfaces and possesses ectopeptidase activity that has no essential enzymatic function for viral entry (Cotten et al. 2013) and the binding of the S1 domain with hDPP44 does not affect the enzymatic activity of the latter (Zhao et al. 2018). Pathogenesis studies have identified the interactions between S protein and hDPP4 (Qian et al. 2013).

Following its initial isolation, MERS-CoV was propagated in African green monkey, rhesus macaque kidney, and other cell lines including human derived cells like Calu-3, HFL, Caco-2, Huh-7, HEK, and His-1 (Shirato et al. 2014); it propagates well in human bronchial and lung tissues. MERS-CoV was more likely to replicate in cell lines derived from camels and goats compared to those from dogs, cats, mice, hamsters, ferrets, and equids indicating that the binding site of MERSCoV varies by species (Zaki et al. 2012; Raj et al. 2014; Meyer et al. 2015; Eckerle et al. 2014; Van Den Brand et al. 2015).

Detailed pathogenesis of MERS-CoV infections in humans or other animals has not been established, but both dromedary and human strains of MERS-CoV have comparable replication (in Vero-E6 cells) and respiratory tropism, and both disrupt the interferon responses (Fehr and Perlman 2015; Scheuplein et al. 2015). In transgenic mouse models, MERS-CoV viral particles were observed in lung, brain, spleen, intestine, and cardiac tissues (Agrawal et al. 2015). The viral cytopathic effects clearly show prominent syncytium formation in humans and in nonhuman primates.

\section{Studies in Animal Models}

Recently, four transgenic mouse models for MERS-CoV infection have been developed as described below (Dawson et al. 2019). 
In the first model, a modified adenovirus hDPP4 was introduced intranasally to mice, which resulted in the expression of hDPP4 in all cells of the lung, not just those that natively express hDPP4. In this model, mice show transient hDPP4 expression and mild lung disease.

In the second model, a transgenic mouse was produced that expressed hDPP4 systemically. In this model, MERS-CoV infection led to high levels of viral RNA and inflammation in the lungs, but significant inflammation and viral RNA were also detected in the brains of infected mice indicating a nonphysiological expression pattern.

In the third model, a novel transgenic humanized mouse model was generated by replacing the mouse DPP4 coding sequence with that encoding (human) hDPP4, ensuring correct physiological expression of hDPP4. Mice in this model showed lung pathology consistent with the radiographic findings of interstitial pneumonia and significant lung disease as seen in humans infected with MERS-CoV.

Finally, in 2016, Cockrell et al. generated a mouse model permissive for MERS$\mathrm{CoV}$ infection, but with functional DPP4 immune function. Infecting this DPP4chimeric mouse with a mouse-adapted strain of MERS-CoV mimics MERS-CoVinduced respiratory disease without bystander neurologic disease (Cockrell et al. 2016). Nonhuman primate models, including the rhesus macaque and common marmoset, have also been reported as suitable animal models of MERS-CoV infection. Rhesus macaques infected with MERS-CoV via intra-tracheal inoculation showed clinical signs of disease, viral replication, histological lesions, and neutralizing antibody production, indicating that this monkey model is suitable for studies of MERS-CoV infection.

\section{Clinical Features of MERS-CoV}

The median age of persons with laboratory-confirmed MERS-CoV infection is 49 years (range, $<1-94$ ); 65\% are males. The median time from illness onset to hospitalization is approximately 4 days, with median length of stays of 41 days (Chafekar and Fielding 2018).

Men aged over 60 years, those with medical co-morbidities, and healthcare workers have the highest risk for acquiring MERS-CoV infection. The median incubation period for human-to-human transmission is approximately 5 days (range 2-15). In addition, most cases in Saudi Arabia have occurred among men, aged 45 years or older, and those living in areas of lower humidity and higher temperatures (Alghamdi et al. 2014). A review of 939 cases in Saudi Arabia found the case fatality rate (CFR) increases with age, ranging from $12.5 \%$ among those 19 years to $86.2 \%$ among those $>80$ years (Dawson et al. 2019).

MERS-CoV causes symptoms similar to that of SARS but with a distinct clinical course and a higher CFR of 35-50\%. Most cases present with symptoms of influenza-like illness (ILI) such as fever, cough (predominantly dry), malaise, myalgia, sore throat, headache, rhinorrhea, nausea, vomiting, abdominal pain, or diarrhea. Dyspnea is a frequent complaint; some patients develop acute kidney 
injury and the majority develop pneumonia (70\%) and ultimately require intensive care unit (ICU) support. Concomitant infections and hypoalbuminemia were identified as the predictors of severe infection in individuals aged $>65$ years. Other features such as circulatory collapse, liver function, and hematological derangements are common in critically ill patients. A second-trimester stillbirth has been reported in a pregnant woman with MERS-CoV (Payne et al. 2014). While MERS-CoV has typically involved adults; a small number of pediatric cases (Al-Tawfiq et al. 2016), including a fatality (Thabet et al. 2015), have been reported to date. Most of the pediatric cases are asymptomatic and found during the screening of close contacts of infected patients in the community or hospital. Children with underlying medical conditions are at higher risk of acquiring MERS-CoV infection. Mortality from MERS-CoV is higher in men and in those with preexisting illnesses (Banik et al. 2016).

MERS-CoV is linked with more severe disease in the elderly, immunocompromised, chronic diseases including cancer, chronic lung disease, and diabetes. The majority of patients who are hospitalized with MERS-CoV infection include the elderly, immunocompromised, or those with co-morbidities such as obesity, diabetes, hypertension, chronic cardiovascular, respiratory, and/or kidney disease (Hajjar et al. 2013).

Laboratory findings include lymphopenia, thrombocytopenia and elevated lactate dehydrogenase, consumptive coagulopathy and elevations in creatinine and liver enzymes in a substantial number of cases (Van Den Brand et al. 2015; Scheuplein et al. 2015; Qian et al. 2013).

Simultaneous infection of the respiratory tract with at least two viruses is common in patients hospitalized with MERS-CoV, but it is not clear whether co-infections result in more or less severe disease compared to MERS-CoV infection alone (Pinky and Dobrovolny 2016). As the clinical features in co-infections are nonspecific, accurate epidemiological studies of etiologic agents require laboratory confirmation of infection. Respiratory viruses that have been detected together with MERS-CoV previously include influenza A virus (Hajjar et al. 2013), respiratory syncytial virus, human parainfluenza-3 virus, and human metapneumovirus (Chafekar and Fielding 2018).

Bacterial co-infections in MERS-CoV infected patients requiring mechanical ventilation include Klebsiella pneumoniae, Staphylococcus aureus, Acinetobacter species, and Candida species within and outside of the respiratory tract (Mohammed et al. 2015). Preceding or concurrent viral respiratory tract infection can predispose the host to secondary co-infections from other pathogens throughout the airway. The mechanisms by which viruses promote these superinfections are diverse (Bakaletz 2017). As yet, not much is known as to how MERS-CoV damages the airway and dysregulate the lung barrier function, which, in turn, supports the adherence and invasion of other pathogens into normally sterile sites within the respiratory tract. 


\section{Laboratory Diagnosis}

Suitable specimens for MERS-CoV testing include those from the upper and lower respiratory tract (such as nasopharyngeal swabs and aspirates, sputum, and bronchoalverolar lavages), serology, and/or stools. Lower respiratory tract samples typically contain the highest viral loads, so should be preferred where possible. Repeat testing (especially of lower respiratory tracts specimens) in clinically compatible cases should be performed if initial results are negative. Appropriate personal protective equipment should be used when collecting and also processing samples to prevent transmission of infection to healthcare and laboratory workers.

In the clinical laboratory, MERS-CoV infection is typically diagnosed using nucleic acid detection methods (Chafekar and Fielding 2018). Serology is useful in cases where nucleic acid is not detected in the individual case, and also to determine population immunity. Virus culture is not routinely performed due to the slower turnaround times, technical expertise, and laboratory containment facilities required (Al-Tawfiq et al. 2016).

Nucleic acid testing algorithms using reverse transcriptase polymerase chain reaction (RT-PCR) typically incorporate a screening, followed by a confirmatory test (Lu et al. 2014). Four targets are commonly used: upstream region of the E (upE) gene, ORF $1 \mathrm{a}$ and $\mathrm{lb}$ and the $\mathrm{N}$ gene. The upE gene is generally used for screening purposes and the other three for confirmatory testing. Where available, the RdRp gene (for the broad detection of $\beta$-coronavirus clade $\mathrm{C}$ ) and/or $\mathrm{N}$ gene sequencing may also be considered for confirmation of infection and also for phylogenetic analysis. As the primers for the RdRp sequencing assay are highly conserved, it is not recommended that this assay be used alone for MERS-CoV confirmation.

Sera samples should be collected during the acute phase of illness, stored and tested in parallel with convalescent sera collected three or more weeks later. If the acute sample was not collected, a single serum sample collected two or more weeks after symptom onset may be tested. For serological testing, both immunofluorescence and neutralization assays are used. Similar to nucleic acid testing, a two stage approach using a screening followed by a confirmatory test can be employed. For screening purposes, an enzyme linked immunosorbent assay (ELISA) against recombinant $\mathrm{N}$ protein can be used, followed by confirmatory testing using a whole virus indirect fluorescent antibody assay test or neutralization. There is considerable difference in the analytical performance of the commercial assays currently available for MERS-CoV testing, with cross-reactivity against other coronaviruses. Other assays that have been developed include the pseudoparticle virus neutralization test ( $\mathrm{ppNT}$ ) for seroepidemiology studies in humans and dromedary camels. 


\section{Management of MERS-CoV}

To date, no approved antiviral therapy or vaccination is available for MERS-CoV infection due to the lack of controlled trials demonstrating efficacy (Mubarak et al. 2019). Various treatment options were previously attempted or suggested based on in vitro experiments or experience from SARS patients (Stockman et al. 2006). To date, experience with treating MERS-CoV is limited to individual case reports or small case series. Omrani et al. (2015) showed that in patients with severe MERS$\mathrm{CoV}$ infection, ribavirin and interferon alfa-2a therapy are significantly associated with improved survival at 14, but not 28 days (Omrani et al. 2015). In vitro studies also suggest that the ribavirin and interferon alpha- $2 \mathrm{~b}$ combination therapy has significant antiviral effect (Carvalho et al. 2014).

Using distinct clones of anti-CD26 monoclonal antibodies, the domains of CD26 involved in the binding of MERS-CoV have been identified (Ohnuma et al. 2013). It has been suggested that 2F9, a clone of CD26, and YS110, a humanized monoclonal antibody against CD26, could be potential therapeutic agents for MERS-CoV (Ohnuma et al. 2013). One of the antibodies, m336, neutralizes the virus with exceptional potency and, therefore, has potential as a candidate drug and could be even useful in vaccine design (Graham 2013). Additionally, human microRNAs might be useful as antiviral therapy against MERS-CoV infection (Dyall et al. 2017). In hospitalized patients, the untested convalescent-phase plasma has been suggested as supportive therapy to minimize the severity of infection (Marano et al. 2016).

A few candidate vaccines have been tested in mice with some promising results (Schindewolf and Menachery 2019). Subunit vaccines based on MERS-CoV spike protein and its RBD could be useful in the development of MERS-CoV vaccine. Inhibiting papain-like or 3C-like proteases of MERS-CoV which regulate the polyproteins in MERS-CoV genomic RNA could be a useful concept in vaccine design (Mielech et al. 2014).

The control of MERS-CoV primarily relies on case-based surveillance, early diagnosis when infection is suspected, and the implementation and strict adherence of infection control measures. The role of respiratory protective equipment such as surgical masks and N95 respirators has been discussed but not yet proven (Smith et al. 2016). A large study is currently underway to examine the role of facemasks against respiratory viruses including MERS-CoV among Hajj pilgrims (Wang et al. 2015), although MERS-CoV transmission at the Hajj has never been reported to date (Alotaibi et al. 2017).

Although person to person transmission is limited, travellers to the Middle East may be at risk of exposure and infection with MERS-CoV. Raising awareness of MERS-CoV transmission is important in view of the fact that many travellers are not aware of MERS-CoV outbreaks (Alqahtani et al. 2016).

It is essential to intensify infection control measures in healthcare settings, particularly through health education and awareness. Healthcare workers also need to follow stringent precautions while treating suspected MERS-CoV patients including using eye shields and other personal protective equipment, particularly when performing aerosol-generating procedures. Immunocompromised individuals and 
those with preexisting medical conditions should avoid close contact with dromedary camels in areas of where the virus is circulating. Similarly, the consumption of raw camel milk and meat and exposure to camel urine should be avoided. Understanding the correlation between the causative factors and susceptibility to MERS$\mathrm{CoV}$ infection is important.

\section{Conclusion}

In conclusion, MERS-CoV is a newly emerged virus mostly prevalent in the Middle East with sustained transmission of infection. As yet there is no specific therapy or vaccine to prevent infection. Travellers to the Arabian Peninsula and where MERS$\mathrm{CoV}$ is circulating should remain vigilant against acquiring infection. They are advised to practice proper hand hygiene, protective behaviors, and cough etiquette. It is also recommended that they avoid exposure to camels and sick individuals and refrain from consuming raw camel products.

\section{References}

Agrawal AS, Garron T, Tao X, Peng BH, Wakamiya M, Chan TS, Couch RB, Tseng CT (2015) Generation of a transgenic mouse model of Middle East respiratory syndrome coronavirus infection and disease. J Virol 89:3659-3670

Al-Ahmadi K, Alahmadi S, Al-Zahrani A (2019) Spatiotemporal clustering of Middle East respiratory syndrome coronavirus (MERS-CoV) incidence in Saudi Arabia, 2012-2019. Int J Environ Res Public Health 16(14):1-11

Alagaili AN, Briese T, Mishra N et al (2014) Middle East respiratory syndrome coronavirus infection in dromedary camels in Saudi. mBio 5:e00884-914

Alghamdi IG, Hussain II, Almalki SS, Alghamdi MS, Alghamdi MM, El-Sheemy MA (2014) The pattern of Middle East respiratory syndrome coronavirus in Saudi Arabia: a descriptive epidemiological analysis of data from the Saudi Ministry of Health. Int J Gen Med 7:417-423

Alotaibi MS, Alsubaie AM, Almohaimede KA, Alotaibi TA, Alharbi OA, Aljadoa AF, Alhamad AH, Barry M (2017) To what extent are Arab pilgrims to Makkah aware of the middle east respiratory syndrome coronavirus and the precautions against it? J Fam Community Med 24:91-96

Alqahtani AS, Wiley KE, Mushta SM, Yamazaki K, Bindhim NF, Heywood AE, Booy R, Rashid H (2016) Association between Australian Hajj Pilgrims' awareness of MERS-CoV, and their compliance with preventive measures and exposure to camels. J Travel Med 23:taw046

Al-Tawfiq JA, Kattan RF, Memish ZA (2016) Middle East respiratory syndrome coronavirus disease is rare in children: an update from Saudi Arabia. World J Clin Pediatr 5:391-396

Arabi YM, Arifi AA, Balkhy HH, Najm H, Aldawood AS, Ghabashi A, Hawa H, Alothman A, Khaldi A, Al Raiy B (2014) Clinical course and outcomes of critically ill patients with Middle East respiratory syndrome coronavirus infection. Ann Intern Med 160:389-397

Bakaletz LO (2017) Viral-bacterial co-infections in the respiratory tract. Curr Opin Microbiol $35: 30-35$

Banik GR, Khandaker G, Rashid H (2015) Middle East respiratory syndrome coronavirus "MERSCoV": current knowledge gaps. Paediatr Respir Rev 16:197-202

Banik GR, Alqahtani AS, Booy R, Rashid H (2016) Risk factors for severity and mortality in patients with MERS-CoV: analysis of publicly available data from Saudi Arabia. Virol Sin $31: 81-84$ 
Carvalho OV, Saraiva GL, Ferreira CG, Felix DM, Fietto JL, Bressan GC, Almeida MR, Silva Junior A (2014) In-vitro antiviral efficacy of ribavirin and interferon-alpha against canine distemper virus. Can J Vet Res 78:283-289

Chafekar A, Fielding BC (2018) MERS-CoV: understanding the latest human coronavirus threat. Viruses 10:93

Chan JF, To KK, Tse H, Jin DY, Yuen KY (2013) Interspecies transmission and emergence of novel viruses: lessons from bats and birds. Trends Microbiol 21:544-555

Cockrell AS, Yount BL, Scobey T, Jensen K, Douglas M, Beall A et al (2016) A mouse model for MERS coronavirus-induced acute respiratory distress syndrome. Nat Microbiol 2:16226

Cotten M, Lam TT, Watson SJ, Palser AL, Petrova V, Grant P, Pybus OG, Rambaut A, Guan Y, Pillay D, Kellam P, Nastouli E (2013) Full-genome deep sequencing and phylogenetic analysis of novel human betacoronavirus. Emerg Infect Dis 19:736-42b

Cunha CB, Opal SM (2014) Middle East respiratory syndrome (MERS): a new zoonotic viral pneumonia. Virulence 5:650-654

Dawson P, Malik MR, Parvez F, Morse SS (2019) What have we learned about Middle East respiratory syndrome coronavirus emergence in humans? A systematic literature review. Vector Borne Zoonotic Dis 19:174-192

De Groot RJ, Baker SC, Baric RS, Brown CS, Drosten C, Enjuanes L, Fouchier RA, Galiano M, Gorbalenya AE, Memish ZA, Perlman S, Poon LL, Snijder EJ, Stephens GM, Woo PC, Zaki AM, Zambon M, Ziebuhr J (2013) Middle East respiratory syndrome coronavirus (MERSCoV): announcement of the Coronavirus Study Group. J Virol 87:7790-7792

Dyall J, Gross R, Kindrachuk J, Johnson RF, Olinger GG Jr, Hensley LE, Frieman MB, Jahrling PB (2017) Middle East respiratory syndrome and severe acute respiratory syndrome: current therapeutic options and potential targets for novel therapies. Drugs 77:1935-1966

ECDC (2019) Communicable disease threats report (CDTR)-Week 49, 1-7 December 2019 [Online]. ECDC. https://www.ecdc.europa.eu/sites/default/files/documents/Communicable-dis ease-threat-report-07-12-2019.pdf. Accessed 30 Dec 2019

Eckerle I, Muller MA, Kallies S, Gotthardt DN, Drosten C (2013) In-vitro renal epithelial cell infection reveals a viral kidney tropism as a potential mechanism for acute renal failure during Middle East respiratory syndrome (MERS) coronavirus infection. Virol J 10:359

Eckerle I, Corman VM, Muller MA, Lenk M, Ulrich RG, Drosten C (2014) Replicative capacity of MERS coronavirus in livestock cell lines. Emerg Infect Dis 20:276-279

FAO (2019) MERS-CoV situation update [Online]. http://www.fao.org/ag/againfo/programmes/en/ empres/mers/situation_update.html. Accessed 30 Dec 2019

Fehr AR, Perlman S (2015) Coronaviruses: an overview of their replication and pathogenesis. Methods Mol Biol 1282:1-23

Graham BS (2013) Advances in antiviral vaccine development. Immunol Rev 255:230-242

Hajjar SA, Memish ZA, Mcintosh K (2013) Middle East respiratory syndrome coronavirus (MERSCoV): a perpetual challenge. Ann Saudi Med 33:427-436

Lu X, Whitaker B, Sakthivel SKK, Kamili S, Rose LE, Lowe L, Mohareb E, Elassal EM, Al-Sanouri T, Haddadin A, Erdman DD (2014) Real-time reverse transcription-PCR assay panel for Middle East respiratory syndrome coronavirus. J Clin Microbiol 52:67-75

Lu R, Wang Y, Wang W, Nie K, Zhao Y, Su J, Deng Y, Zhou W, Li Y, Wang H, Wang W, Ke C, Ma X, Wu G, Tan W (2015) Complete genome sequence of Middle East respiratory syndrome coronavirus (MERS-CoV) from the first imported MERS-CoV case in China. Genome Announc 4:e00818-15

Marano G, Vaglio S, Pupella S, Facco G, Catalano L, Liumbruno GM, Grazzini G (2016) Convalescent plasma: new evidence for an old therapeutic tool? Blood Transfus 14:152-157

Memish ZA (2014) MERS-CoV an emerging viral zoonotic disease: three years after and counting. Recent Pat Antiinfect Drug Discov 9:159-60

Meyer B, Garcia-Bocanegra I, Wernery U, Wernery R, Sieberg A, Muller MA, Drexler JF, Drosten C, Eckerle I (2015) Serologic assessment of possibility for MERS-CoV infection in equids. Emerg Infect Dis 21:181-182 
Mielech AM, Kilianski A, Baez-Santos YM, Mesecar AD, Baker SC (2014) MERS-CoV papainlike protease has deISGylating and deubiquitinating activities. Virology 450-451:64-70

Mohammed MS, Khalid HS, Muddathir AE, El-Tahir K, Khan AA, Algadir HA, Osman WJ, Siddiqui NA (2015) Effect of some plants' extracts used in Sudanese folkloric medicines on carrageenan-induced inflammation. Pak J Pharm Sci 28:159-165

Mubarak A, Alturaiki W, Hemida MG (2019) Middle East respiratory syndrome coronavirus (MERS-CoV): infection, immunological response, and vaccine development. J Immunol Res 2019:6491738

Muller MA, Corman VM, Jores J, Meyer B, Younan M, Liljander A, Bosch BJ, Lattwein E, Hilali M, Musa BE, Bornstein S, Drosten C (2014) MERS coronavirus neutralizing antibodies in camels, Eastern Africa, 1983-1997. Emerg Infect Dis 20:2093-2095

Ohnuma K, Haagmans BL, Hatano R, Raj VS, Mou H, Iwata S, Dang NH, Bosch BJ, Morimoto C (2013) Inhibition of Middle East respiratory syndrome coronavirus infection by anti-CD26 monoclonal antibody. J Virol 87:13892-13899

Omrani AS, Al-Tawfiq JA, Memish ZA (2015) Middle East respiratory syndrome coronavirus (MERS-CoV): animal to human interaction. Pathog Glob Health 109:354-362

Payne DC, Iblan I, Alqasrawi S, Al Nsour M, Rha B, Tohme RA, Abedi GR, Farag NH, Haddadin A, Al Sanhouri T, Jarour N, Swerdlow DL, Jamieson DJ, Pallansch MA, Haynes LM, Gerber SI, Al Abdallat MM (2014) Stillbirth during infection with Middle East respiratory syndrome coronavirus. J Infect Dis 209:1870-1872

Pinky L, Dobrovolny HM (2016) Coinfections of the respiratory tract: viral competition for resources. PLoS One 11:e0155589

Qian Z, Dominguez SR, Holmes KV (2013) Role of the spike glycoprotein of human Middle East respiratory syndrome coronavirus (MERS-CoV) in virus entry and syncytia formation. PLoS One 8:e76469

Raj VS, Smits SL, Provacia LB, Van Den Brand JM, Wiersma L, Ouwendijk WJ, Bestebroer TM, Spronken MI, Van Amerongen G, Rottier PJ, Fouchier RA, Bosch BJ, Osterhaus AD, Haagmans BL (2014) Adenosine deaminase acts as a natural antagonist for dipeptidyl peptidase 4-mediated entry of the Middle East respiratory syndrome coronavirus. J Virol 88:1834-1838

Ramadan N, Shaib H (2019) Middle East respiratory syndrome coronavirus (MERS-CoV): a review. Germs 9:35-42

Scheuplein VA, Seifried J, Malczyk AH, Miller L, Hocker L, Vergara-Alert J, Dolnik O, Zielecki F, Becker B, Spreitzer I, Konig R, Becker S, Waibler Z, Muhlebach MD (2015) High secretion of interferons by human plasmacytoid dendritic cells upon recognition of Middle East respiratory syndrome coronavirus. J Virol 89:3859-3869

Schindewolf C, Menachery VD (2019) Middle East respiratory syndrome vaccine candidates: cautious optimism. Viruses 11:74

Senga M, Arabi YM, Fowler RA (2017) Clinical spectrum of the Middle East respiratory syndrome coronavirus (MERS-CoV). J Infect Public Health 10:191-194

Shapiro M, London B, Nigri D, Shoss A, Zilber E, Fogel I (2016) Middle East respiratory syndrome coronavirus: review of the current situation in the world. Disaster Mil Med 2:9

Shirato K, Yano T, Senba S, Akachi S, Kobayashi T, Nishinaka T, Notomi T, Matsuyama S (2014) Detection of Middle East respiratory syndrome coronavirus using reverse transcription loopmediated isothermal amplification (RT-LAMP). Virol J 11:139

Smith JD, Macdougall CC, Johnstone J, Copes RA, Schwartz B, Garber GE (2016) Effectiveness of N95 respirators versus surgical masks in protecting health care workers from acute respiratory infection: a systematic review and meta-analysis. CMAJ 188:567-574

Song W, Wang Y, Wang N, Wang D, Guo J, Fu L, Shi X (2014) Identification of residues on human receptor DPP4 critical for MERS-CoV binding and entry. Virology 471-473:49-53

Song D, Ha G, Serhan W, Eltahir Y, Yusof M, Hashem F, Elsayed E, Marzoug B, Abdelazim A, Al Muhairi S (2015) Development and validation of a rapid immunochromatographic assay for detection of Middle East respiratory syndrome coronavirus antigen in dromedary camels. J Clin Microbiol 53:1178-1182 
Stockman LJ, Bellamy R, Garner P (2006) SARS: systematic review of treatment effects. PLoS Med 3:e343

Su S, Wong G, Liu Y, Gao GF, Li S, Bi Y (2015) MERS in South Korea and China: a potential outbreak threat? Lancet 385:2349-2350

Thabet F, Chehab M, Bafaqih H, Al Mohaimeed S (2015) Middle East respiratory syndrome coronavirus in children. Saudi Med J 36:484-486

Van Den Brand JM, Smits SL, Haagmans BL (2015) Pathogenesis of Middle East respiratory syndrome coronavirus. J Pathol 235:175-184

Van Doremalen N, Munster VJ (2015) Animal models of Middle East respiratory syndrome coronavirus infection. Antivir Res 122:28-38

Wang N, Shi X, Jiang L, Zhang S, Wang D, Tong P, Guo D, Fu L, Cui Y, Liu X, Arledge KC, Chen YH, Zhang L, Wang X (2013) Structure of MERS-CoV spike receptor-binding domain complexed with human receptor DPP4. Cell Res 23:986-993

Wang Q, Qi J, Yuan Y, Xuan Y, Han P, Wan Y, Ji W, Li Y, Wu Y, Wang J, Iwamoto A, Woo PC, Yuen KY, Yan J, Lu G, Gao GF (2014) Bat origins of MERS-CoV supported by bat coronavirus HKU4 usage of human receptor CD26. Cell Host Microbe 16:328-337

Wang M, Barasheed O, Rashid H, Booy R, El Bashir H, Haworth E, Ridda I, Holmes EC, Dwyer DE, Nguyen-Van-Tam J (2015) A cluster-randomised controlled trial to test the efficacy of facemasks in preventing respiratory viral infection among Hajj pilgrims. J Epidemiol Glob Health 5:181-189

Yang L, Wu Z, Ren X, Yang F, Zhang J, He G, Dong J, Sun L, Zhu Y, Zhang S, Jin Q (2014) MERSrelated betacoronavirus in Vespertilio superans bats, China. Emerg Infect Dis 20:1260-1262

Yusof MF, Eltahir YM, Serhan WS, Hashem FM, Elsayed EA, Marzoug BA, Abdelazim AS, Bensalah OK, Al Muhairi SS (2015) Prevalence of Middle East respiratory syndrome coronavirus (MERS-CoV) in dromedary camels in Abu Dhabi Emirate, United Arab Emirates. Virus Genes 50:509-513

Zaki AM, Van Boheemen S, Bestebroer TM, Osterhaus AD, Fouchier RA (2012) Isolation of a novel coronavirus from a man with pneumonia in Saudi Arabia. N Engl J Med 367:1814-1820

Zhao G, He L, Sun S, Qiu H, Tai W, Chen J, Li J, Chen Y, Guo Y, Wang Y, Shang J, Ji K, Fan R, Du E, Jiang S, Li F, Du L, Zhou Y (2018) A novel nanobody targeting Middle East respiratory syndrome coronavirus (MERS-CoV) receptor-binding domain has potent cross-neutralizing activity and protective efficacy against MERS-CoV. J Virol 92:e00837-e00818

Zumla A, Hui DS (2014) Infection control and MERS-CoV in health-care workers. Lancet 383:1869-1871

Zumla A, Hui DS, Perlman S (2015) Middle East respiratory syndrome. Lancet 386:995-1007 